\title{
Numerical Investigation of Turbulent Premixed Combustion of Methane / Air in Low Swirl Burner under Elevated Pressures and Temperatures
}

\author{
Akram Ben $\mathrm{Ali}^{12^{* *}}$, Mansour Karkoub ${ }^{3}$, Mouldi Chrigui ${ }^{2,4}$ \\ ${ }^{1}$ Department of Mechanical Engineering, Ecole National d'Ingénieurs de Tunis, Tunis 1002, Tunisia \\ ${ }^{2}$ Mechanical Modeling Energy and Materials Research Unit, Ecole National d'Ingénieurs de Gabes, Gabes 6029, Tunisia \\ ${ }^{3}$ Department of Mechanical Engineering, Texas A\&M University, Doha, Qatar \\ ${ }^{4}$ Institute for Energy and Powerplant Technology, Darmstadt University of Technology, Darmstadt 64277, Germany
}

Corresponding Author Email: akram.benali@enit.utm.tn

https://doi.org/10.18280/ijht.390116

Received: 4 May 2020

Accepted: 21 December 2020

\section{Keywords:}

combustion, low swirl burner, turbulence, computational fluid dynamics, large eddy simulation, Reynolds averaged NavierStockes

\begin{abstract}
Turbulent combustion modeling of lean premixed methane/air gas mixture in a low swirl burner is carried out using Large Eddy Simulation (LES). The operating conditions of the experiment as well as simulation are carried out at elevated pressure and temperature. The first case-simulation is a premixed combustion model based on C-equation formulation, the second one is based on species transport - Eddy Dissipation Concept (EDC) model. Numerical results for axial velocity and turbulence intensity along the centerline showed a good agreement against the experimental data. Quantitative results of $\mathrm{OH}$ mass fraction contour showing the flame structure are in a plausible agreement compared to the experimental measurement.
\end{abstract}

\section{INTRODUCTION}

With the increasing demand on energy, saving the environment becomes a real challenge. Regulations regarding pollution are more stringent. Lean premixed combustion appears to be a solution for a cleaner combustion with less NOx emissions [1]. Using this method is challenging due to risks of instabilities, auto-ignition and flame-flashback [2], which makes a challenge for engineers to develop innovative designs for combustion systems which can guarantee operation of combustors in a safe and stable conditions.

Low swirl burner (LSB) was introduced by Bédat and Cheng [3]. The fuel/oxidizer mixture enters the combustion chamber through two inlets; a swirled flow inlet, and an axial flow passages (holes). Axial flow passes through perforated plate. This device demonstrated its ability to enhance the rate of combustion. Due to swirl condition, recirculation zones build up, causing the flame to stabilize in the region where the mean burning speed equals the axial flow velocity [4].

Beerer [5] investigated flame flashback and stability limits, pollutant emissions, the effect of inlet temperature, firing temperature, and flow rate on the combustion process. His experimental results confirmed the linear dependence between turbulent flame speed and turbulence intensity at the flame front for methane and hydrogen flames.

Colorado and McDonell [6] examined NOx emissions and lean blow off (LBO) stability limits of natural gas and biogas fuels. Flame was stabilized using a low swirl burner with two injector configurations; quarl (conic) expansion nozzle and sudden expansion nozzle. The latter showed better results in terms of low NOx emissions but with relatively narrow stability range.

Xiao et al. [7] investigated flow-field and flame behaviors associated with a low-swirl burner in atmospheric conditions.
It was verified that the flow velocity decays linearly in the burner region.

In addition to experimental studies, computational models for combustion in LSB is mandatory for a better design of the burner. It also allowed a better prediction of combustor behavior under different operation conditions. Mainly two numerical models are currently used for turbulence modeling in industry and academy. They are Reynolds Averaged Navier Stockes model (RANS) and Large Eddy Simulation (LES). Neumayer and Hirsch [8] conducted RANS simulations to predict the position and shape of premixed lean methane flame. He conducted RANS simulations for methane/air combustion in a low swirl burner. Two combustion models were used; premixed combustion (TFC) and species transport (EDC). The former gave better prediction for flame shape and position.

With the increasing availability of high-performance computational resources, large eddy simulation appears to be a promising numerical tool to model turbulent combustion in a very good accuracy compared to RANS model. Nogenmyr et al. [9] used different Large Eddy Simulations (LES) models for reactive flows to simulate swirling lean premixed methane/air flame and compared it with experimental results on an atmospheric-pressure laboratory swirl burner. Nogenmyr et al. [10] in utilized LES-based finite rate chemistry solver to emphasize velocity and temperature distributions of confined and unconfined flames. LES predicted with adequate accuracy both flames (open and confined). Using wall temperature data from experiment was essential to have good simulation results.

Previous studies have demonstrated that LES showed an acceptable performance to predict combustion in low swirl burner mainly in atmospheric pressure condition.

The goal of this work is to complement the simulation works and cover combustion under elevated pressure and 
temperature conditions. The flame behavior in these conditions, i.e. in a low swirl burner, needs to be fully understood. Numerical investigations using different turbulence and combustion models were carried out to get a better understanding of flame structure and flow field velocity distribution for lean premixed methane. Effects of elevated pressure and temperature are important parameters in modeling the laminar flame speed which in turn, highly influence the behavior of the combustion of a premixed flame.

\section{GOVERNING EQUATIONS}

\subsection{Large eddy simulation-WALE model}

The model consists of filtering the Navier-Stockes equations where the large eddies are resolved, and the small eddies are modeled. Subgrid-scale turbulent stresses are computed using:

$$
\tau_{i j}-\frac{1}{3} \tau_{k k} \delta_{i j}=-2 \mu_{t} \tilde{S}_{i j}
$$

$\tilde{S}_{i j}$ is the rate-of-strain tensor for the resolved scale given by:

$$
\tilde{S}_{i j} \equiv \frac{1}{2}\left(\frac{\partial \tilde{u}_{i}}{\partial x_{j}}+\frac{\partial \tilde{u}_{j}}{\partial x_{i}}\right)
$$

where:

$\mu_{\mathrm{t}}=$ Subgrid-scale turbulent viscosity.

WALE model computes the subgrid-scale turbulent viscosity $\mu_{\mathrm{t}}$, expressed as:

$$
\mu_{t}=\rho L_{s}^{2} \frac{\left(S_{i j}^{d} S_{i j}^{d}\right)^{3 / 2}}{\left(\tilde{S}_{i j} \tilde{S}_{i j}\right)^{5 / 2}+\left(S_{i j}^{d} S_{i j}^{d}\right)^{5 / 4}}
$$

where, $L_{s}$ and $S_{i j}^{d}$ are given by:

$$
\begin{gathered}
L_{s}=\min \left(k d, C_{w} V^{1 / 3}\right) \\
S_{i j}^{d}=\frac{1}{2}\left(\tilde{g}_{i j}^{2}+\tilde{g}_{j i}^{2}\right)-\frac{1}{3} \delta_{i j} \tilde{g}_{k k}^{2}
\end{gathered}
$$

where:

$$
C_{w}=0.325 \text { and } \tilde{g}_{j i}=\frac{\partial \widetilde{u}_{i}}{\partial x_{j}}
$$

\subsection{Species transport: Eddy Dissipation Concept (EDC)}

This turbulence-chemistry interaction model is based on the work of Magnussen [11], it allows to calculate the net production rate of individual species in turbulent flow for a multi-step reaction mechanism which is the case in this work, It assumes that reaction occurs in small turbulent structures, called the fine scales. Fine scales are length fraction $\xi^{*}$ and time scale $\tau^{*}$. Species reacts in the volume fraction $\xi^{* 3}$ within the time scale $\tau^{*}$. These quantities are expressed as:

$$
\xi^{*}=C_{\xi}\left(\frac{v \varepsilon_{s g s}}{q_{s g s}^{2}}\right)^{\frac{1}{4}}
$$

where:
$C_{\xi}$ length constant equals to 2.1377 .

$v=$ kinematic viscosity.

$\varepsilon_{s g s}=$ sub-grid scale turbulent eddy dissipation.

$q_{s g s}=$ sub-grid scale turbulent kinetic energy.

$$
\tau^{*}=C_{\tau}\left(\frac{v}{\varepsilon}\right)^{\frac{1}{2}}
$$

where:

$C_{\tau}$ time scale constant equals to 0.4082 .

\subsection{Premixed combustion: C-Equation formulation}

The premixed combustion model considers the reacting flow field to be divided into regions of burnt and unburnt species, separated by the flame sheet. Reaction progress variable denoted by "c" represents burnt mixture when equals to 1 and unburnt mixture when equal to 0 . Values between 0 and 1 implies flames front spent some time in burnt state and some in unburnt state.

In order to model the flame front propagation, mean reaction progress variable denoted by $\bar{c}$ is calculated using the equation:

$$
\frac{\partial}{\partial t}(\rho \tilde{c})+\nabla \cdot(\rho \vec{v} \tilde{c})=\nabla \cdot\left(\frac{\mu_{t}}{S c_{t}} \nabla \tilde{c}\right)+\rho S_{c}
$$

where:

$\tilde{c}=$ filtered reaction progress variable.

$S c_{t}=$ turbulent Schmidt number.

$S_{c}=$ reaction progress source term.

\section{EXPERIMENT}

Data in this work were taken from the experiment conducted by Beerer [5] in the University of Irvine, California to explore lean premixed of methane/air mixture combustion in low swirl burner. A high-pressure vessel low swirl burner with sudden expansion are used in the experiment as shown in Figure 1.

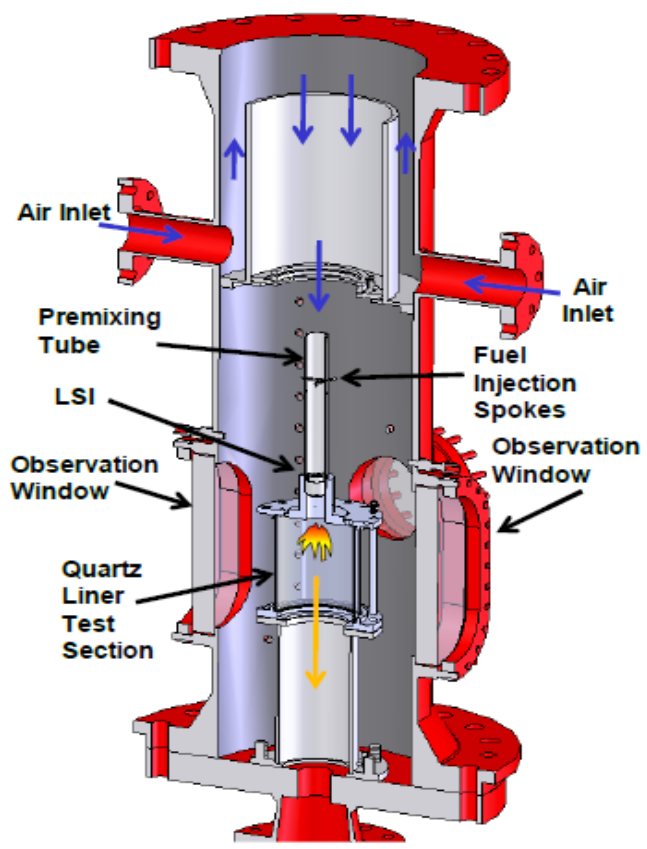

(a) Cross section of the pressure vessel 


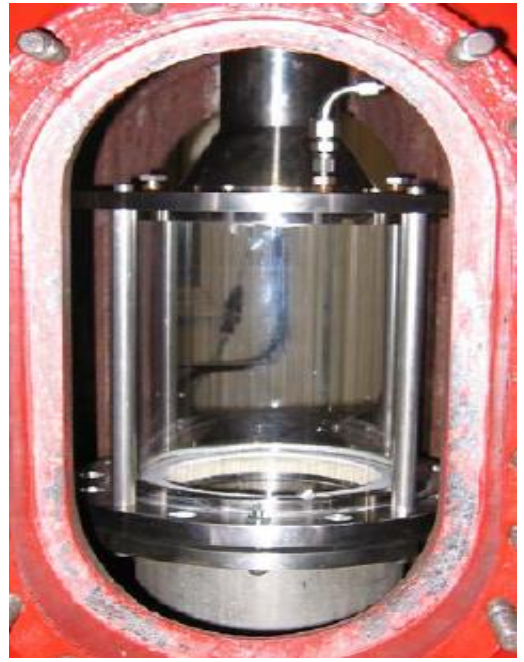

(b) Photograph of test section

Figure 1. Pressure vessel and combustor test section [5]

The flow coming from the premixing tube passes to the low swirl injector where it enters the injector through two inlets, outer inlet or swirl inlet (consists of 16 aero-vanes of $37^{\circ}$ ) where, the flow is swirled, the second inlet is the axial inlet where the flow passes through 25 holes of $2.6 \mathrm{~mm}$ (Figure 2).

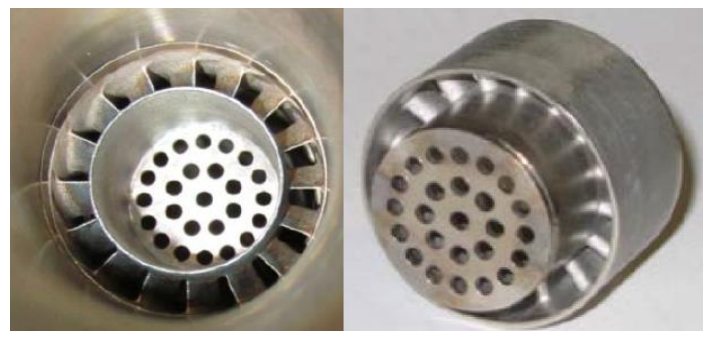

Figure 2. Low swirl injector upstream face (left) and downstream face (right) [5]

$\mathrm{Nd}$ : YAG laser emitting light with a frequency of $10 \mathrm{~Hz}$ is used for the ignition. Laser Doppler Velocimetry (LDV) equipment is used in the experiment in order to measure r.m.s and mean velocities. Main parameters for the experiment are listed in the Table 1:

Table 1. Experiment parameters

\begin{tabular}{cc}
\hline Parameters & Values \\
\hline Operating pressure & $416136 \mathrm{~Pa}$ \\
Fuel (CH4) & $100 \%$ \\
Equivalence ratio & 0.715 \\
Inlet temperature of fuel-air mixture & $418 \mathrm{~K}$ \\
Adiabatic flame temperature & $1943 \mathrm{~K}$ \\
Total mass flow rate & $0.194 \mathrm{~kg} / \mathrm{s}$ \\
Heat release of combustion & $387 \mathrm{~kW}$ \\
\hline
\end{tabular}

\section{NUMERICAL SETUP}

\subsection{Geometry meshing and models}

Methane combustion in low swirl burner is simulated using Reynolds Averaged Navier-Stockes (RANS) turbulence model, then large eddy simulation (LES) turbulence modeling for a 3D geometry (Figure 3).
Unstructured hexahedral mesh for the 3D geometry was generated for the simulation, the total number of cells is $3,435,420$ cells and the minimum Orthogonal Quality was 0.7 .

For RANS simulations, $\mathrm{K}$ epsilon realizable turbulence model was used for all simulations.

For LES simulations WALE Subgrid-Scale Model is used.

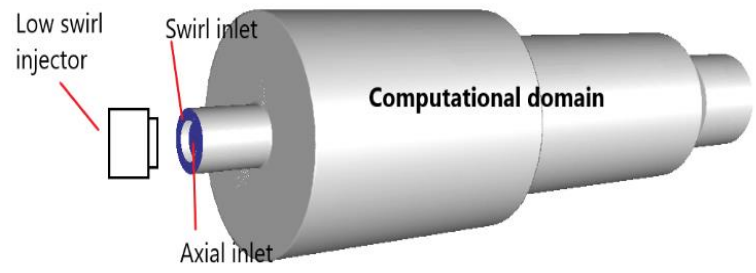

Figure 3. Low swirl burner geometry

\subsection{Boundary conditions}

Simulations boundary condition, in Table 2, are used.

Table 2. Boundary conditions

\begin{tabular}{cc}
\hline Parameters & Values \\
\hline Temperature at Inlet & $418 \mathrm{~K}$ \\
Mass flow rate air & $0.1862 \mathrm{~kg} / \mathrm{s}$ \\
Mass flow rate Methane & $0.0077 \mathrm{~kg} / \mathrm{s}$ \\
Total mass flow rate & 0.1939 \\
Turbulent intensity in axial inlet & $26 \%$ \\
Turbulent intensity in swirl inlet & $26 \%$ \\
Turbulent length scale in axial inlet & $2.6 \mathrm{~mm}$ \\
Turbulent length scale in swirl inlet & $7 \mathrm{~mm}$ \\
\hline
\end{tabular}

\subsection{Reynolds Averaged Navier-Stockes (RANS) simulations}

In the first simulation, premixed combustion model is used, Zimont flame speed model is adopted, in the second simulation, Species transport model is used as species model with Eddy-Dissipation Concept for Turbulence-Chemistry interaction modeling.

\subsection{Large Eddy simulation (LES)}

Two Precursor RANS simulations are carried out. In both simulations $\mathrm{k}-\varepsilon$ turbulence model is used.

Each simulation is used as initial condition for two LES.

In the first LES, the turbulent chemistry model is eddy dissipation concept EDC. Reaction mechanism used to model the chemical reaction is a "skeletal mechanism" including 22 species of the methane combustion based on GRI 3.0 [12].

In the second LES, species transport model based on cequation formulation is used.

Transport equation for the reaction progress variable is solved employing Zimont model.

Values of averaged axial velocity and turbulence intensity were an average value of 2736 samples after 3 times flowthrough.

\section{RESULTS AND DISCUSSION}

Figure 4 depicts the flame structure. The contour of $\mathrm{OH}$ is used to predict the flame position. $\mathrm{OH}$ radicals' concentration 
can be deduced from the photo taken from the experiment [5] where $\mathrm{OH}^{*}$ radical is in blue color.

Reaction progress can be deduced from contour of $\mathrm{OH}$ in EDC model and contour of reaction progress variable in the premixed combustion model (c-equation model).

Maximum mass fraction value of $\mathrm{OH}$ is $8.64 .10^{-4}$ which corresponds to the maximum combustion rate, is located downstream the nozzle exit, see Figure 4 (a). In the same region the strain rate is minimum which implies that combustion is close to the chemical equilibrium, thus the chemical reaction rate reaches the maximum. Over both simulations, EDC model delivers a better prediction than the premixed model.

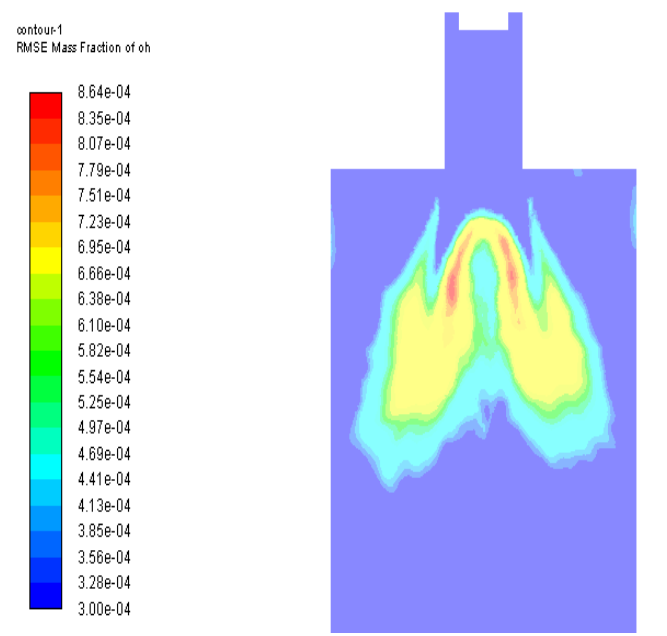

(a) Instantaneous Contour of mass fraction of $\mathrm{OH}$

contour-1
Mean Reaction Progress
\begin{tabular}{|l|l|}
$1.00 \mathrm{e}+00$ \\
$9.50 \mathrm{e}-01$ \\
$9.00 \mathrm{e}-01$ \\
$8.50 \mathrm{e}-01$ \\
$8.00 \mathrm{e}-01$ \\
$7.50 \mathrm{e}-01$ \\
$7.00 \mathrm{e}-01$ \\
$6.50 \mathrm{e}-01$ \\
$6.00 \mathrm{e}-01$ \\
$5.50 \mathrm{e}-01$ \\
$5.00 \mathrm{e}-01$ \\
$4.50 \mathrm{e}-01$ \\
$4.00 \mathrm{e}-01$ \\
$3.50 \mathrm{e}-01$ \\
$3.00 \mathrm{e}-01$ \\
$2.50 \mathrm{e}-01$ \\
$2.00 \mathrm{e}-01$ \\
$1.50 \mathrm{e}-01$ \\
$1.00 \mathrm{e}-01$ \\
$5.00 \mathrm{e}-02$ \\
$0.00 \mathrm{e}+00$
\end{tabular}

(b) Contour of reaction progress

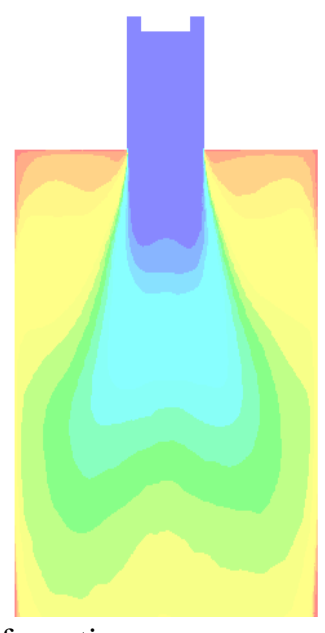

Figure 4. Fraction of $\mathrm{OH}$ mass fraction and reaction progress

Figure 5 Shows simulations results for axial velocity along the centerline. Cheng and Littlejohn [13] calculated the turbulent flame speed using the correlation:

$$
S_{T}=2.1 \times u^{\prime}
$$

where, $u^{\prime}$ is the r.m.s axial velocity. The same equation is used in the simulations.

Numerical values for axial velocity are close to the experimental results. Swirling flow will expand radially and hence axial velocity in centerline should decrease following mass conservation principle. Further downstream, the axial velocity decreases linearly. In the flame lift-off position, the axial velocity increases due to the energy added by the reaction.

$\mathrm{C}$-equation model provided an accurate prediction of the axial velocity at flame lift-off position which is located at 6 $\mathrm{mm}$ downstream the sudden expansion. The axial velocity value given by the model is equal to $13.7 \mathrm{~m} / \mathrm{s}$ which corresponds to the experimental value shown in Figure 5.

A difference between the experimental and EDC model values of the axial velocity is recorded. This difference is positive at the sudden expansion, then it becomes negative further downstream. This is most probably derived from the nature of methane combustion which has a rapid chemistry having a high Damkohler number. The axial velocity is under predicted by EDC model. The latter has tendency to better predict slower combustion. However, C-equation model showed better ability to predict axial velocity values involved in fast chemistry.

The experimental and simulation results of turbulence intensity are shown in Figure 6. Turbulence intensity values range is between $9 \%$ and $17 \%$. There is no decay of the TI (Turbulence intensity) through the perforated axial inlet.

Pope mention that turbulence intensity decays downward from a perforated plate [14], which is not happening in the experiment for the low swirl burner because of the energy added from the swirled flow to the inner flow. This is validated in the simulations.

\section{Axial velocity in centerline - 3D simulations}

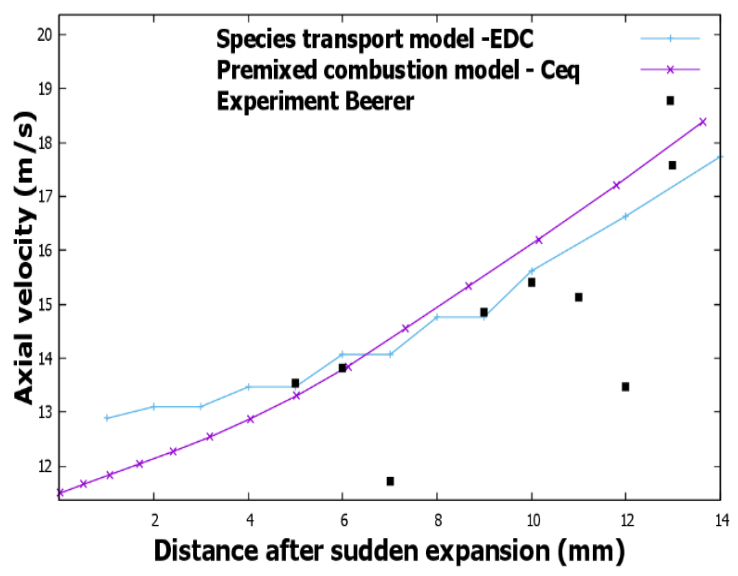

Figure 5. Axial velocity in centerline for LES (EDC and Premixed models)

\section{Turbulence intensity in centerline}

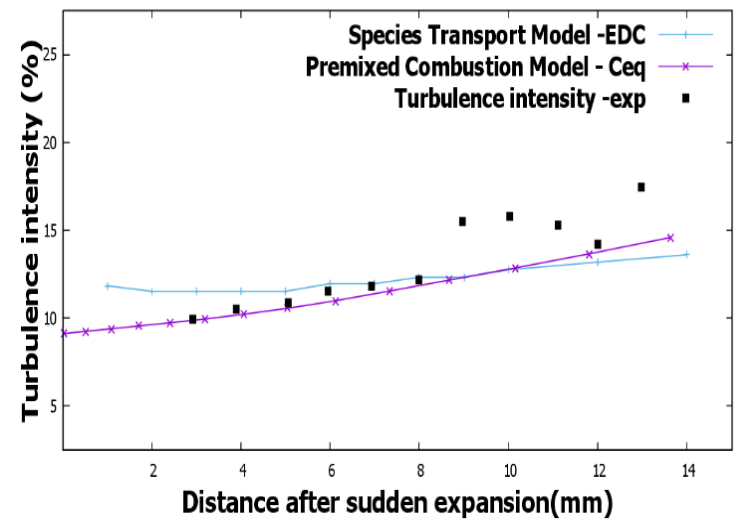

Figure 6. Turbulence intensity in centerline for LES (EDC and Premixed models) 
For the EDC model, the turbulence intensity seems to be homogeneous as it remains around the value of $12 \%$ along the centerline. Whereas, for C-equation model, an increase of turbulence intensity from $9 \%$ to $14 \%$ is registered. This is confirmed by the fact that the predicted gradient of the mean velocity is larger for the C-equation compared to EDC. The mean velocity gradient are production terms for the turbulence, therefore the turbulence intensity provided by $\mathrm{C}$-equation shows a higher slope (Figure 6).

A qualitative comparison between $\mathrm{CH} 4$ mass fraction in EDC model using LES and EDC using RANS is shown in Figure 7 and contour of mass fraction of $\mathrm{CH} 4$ for RANS from literature. The former is conducted in this work, the latter are results of the work of Neumayer [8]. LES shows a superior capability to predict the flame shape and species distribution compared to RANS.

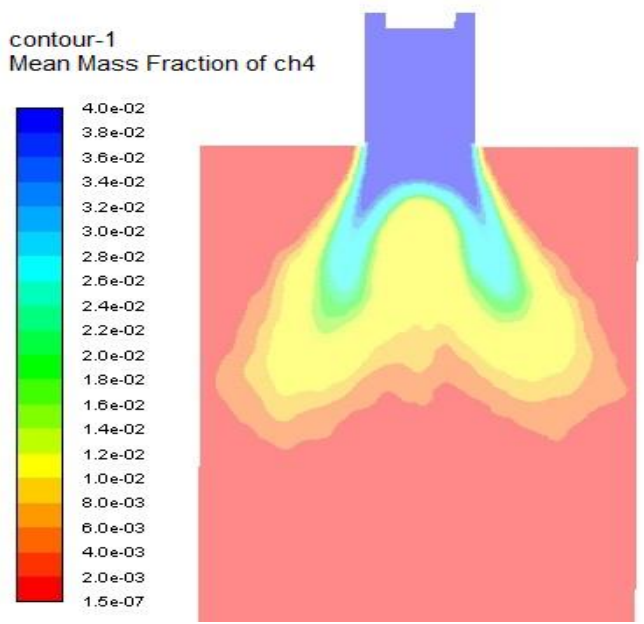

(a) EDC model with LES

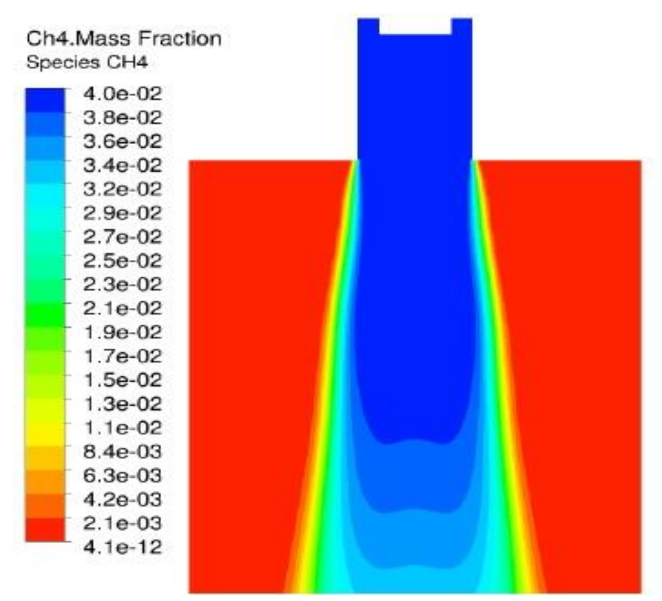

(b) EDC model with RANS

Figure 7. Mean mass fraction of $\mathrm{CH}_{4}$

\section{CONCLUSION}

Two LES models using EDC and Premixed model (Cequation) of lean premixed methane-air flame in low swirl burner are carried out. Mean values of axial velocity along the centerline are considered for both models and then validated by the experimental results.

Both simulations data of rms axial velocity and turbulence intensity along the centerline showed a good agreement with the experimental data.
Using large eddy simulation with EDC model provided acceptable prediction of species mass fraction and flame liftoff position.

A qualitative comparison between experimental flame image and contour of mass fraction of $\mathrm{OH}$ specie demonstrates that LES reproduced successfully the flame shape, not only the external shape but also it gave the information that the flame is lifted off and propagates freely downstream the sudden expansion.

The good prediction of the flame shape relies on the detailed chemistry solved by the EDC.

EDC is more appropriate to slower chemistry, whereas methane combustion as it is used in this work showed a high Damkohler number (rapid chemistry).

Large eddy simulation combined with premixed combustion model (C-equation formulation), was employed to predict turbulence intensity and axial velocity values along the centerline. The produced results were in a good agreement with the experimental data. The flame shape could not be presented using $\mathrm{C}$-equation as the chemistry is reduced to the reaction progress variable. They have been no detailed reaction mechanism for the transport of the species, yet the location of the flame is well predicted using $\mathrm{C}$-equation.

RANS results, from literature, failed to reproduce the flame shape and position. LES showed a good agreement compared to measurement.

A further investigation using a partially premixed combustion along with Flamelet Generated Manifold model (FGM) is going to be conducted. Simulation can be performed to investigate the flame stability in different conditions like flashback and blow off and pollutant emissions.

\section{REFERENCES}

[1] Johnson, M.R., Littlejohn, D., Nazeer, W.A., Smith, K.O., Cheng, R.K. (2005). A comparison of the flowfields and emissions of high-swirl injectors and lowswirl injectors for lean premixed gas turbines. Proceedings of the Combustion Institute, 30(2): 28672874. https://doi.org/10.1016/j.proci.2004.07.040

[2] Lefebvre, A.H. (1999). Gas Turbine Combustion. 2nd ed. a cura di, Philadelphia, PA: Taylor and Francis.

[3] Bedat, B., Cheng, R.K. (1995). Experimental study of premixed flames in intense isotropic turbulence. Combustion and Flame, 100(3): 485-494. https://doi.org/10.1016/0010-2180(94)00138-I

[4] Bell, J.B., Cheng, R.K., Day, M.S., Beckner, V.E., Lijewski, M.J. (2008). Interaction of turbulence and chemistry in a low-swirl burner. In J. Phys.: Conf. Ser, 125: $\quad 012027 . \quad$ https://doi.org/10.1088/1742$6596 / 125 / 1 / 012027$

[5] Beerer, D.J. (2013). Combustion characteristics and performance of low-swirl injectors with natural gas and alternative fuels at elevated pressures and temperatures. University of California, Irvine.

[6] Colorado, A., McDonell, V. (2018). Emissions and stability performance of a low-swirl burner operated on simulated biogas fuels in a boiler environment. Applied Thermal Engineering, 130: 1507-1519. https://doi.org/10.1016/j.applthermaleng.2017.11.047

[7] Xiao, Y., Cao, Z., Wang, C. (2018). Flame stability limits of premixed low-swirl combustion. Advances in Mechanical Engineering, 10(9): 1687814018790878. 


\section{https://doi.org/10.1177/1687814018790878}

[8] Neumayer, M., Hirsch, C. (2013). RANS simulation of methane combustion in a low swirl burner. unpublished thesis M. Sc. thesis-Technische Universität München, Munich-Germany.

[9] Nogenmyr, K.J., Fureby, C., Bai, X.S., Petersson, P., Collin, R., Linne, M. (2009). Large eddy simulation and laser diagnostic studies on a low swirl stratified premixed flame. Combustion and Flame, 156(1): 25-36. https://doi.org/10.1016/j.combustflame.2008.06.014

[10] Nogenmyr, K.J., Cao, H.J., Chan, C.K., Cheng, R.K. (2013). Effects of confinement on premixed turbulent swirling flame using large eddy simulation. Combustion Theory and Modelling, 17(6): 1003-1019. https://doi.org/10.1080/13647830.2013.820842

[11] Magnussen, B. (1981). On the structure of turbulence and a generalized eddy dissipation concept for chemical reaction in turbulent flow. In 19th Aerospace Sciences Meeting, 42. https://doi.org/10.2514/6.1981-42

[12] Karalus, M.F., Fackler, K.B., Novosselov, I.V., Kramlich, J.C., Malte, P.C. (2013). A skeletal mechanism for the reactive flow simulation of methane combustion. In Turbo Expo: Power for Land, Sea, and Air, 55119: V01BT04A065. https://doi.org/10.1115/GT2013-95904

[13] Cheng, R.K., Littlejohn, D. (2008). Effects of combustor geometry on the flowfields and flame properties of a lowswirl injector. International Gas Turbine Institute, 43130: 393-407. https://doi.org/10.1115/GT2008-50504

[14] Pope, S.B. (2000). Turbulent Flows. Cambridge University https://doi.org/10.1017/CBO9780511840531

\section{NOMENCLATURE}

$S_{T} \quad$ Turbulent flame speed, $\mathrm{m} . \mathrm{s}^{-1}$

$u^{\prime} \quad$ Root-mean-square axial velocity, $\mathrm{m} . \mathrm{s}^{-1}$

$L_{s} \quad$ Mixing length for subgrid scales, $\mathrm{m}$

c Reaction progress variable

$\tilde{c} \quad$ filtered reaction progress variable

$S c_{t} \quad$ turbulent Schmidt number

$S_{c} \quad$ Reaction progress source term length constant

$C_{\xi} \quad$ length constant

$C_{\tau} \quad$ time scale constant

$q_{s g s} \quad$ sub-grid scale turbulent kinetic energy

$\widetilde{S}_{i j} \quad$ rate-of-strain tensor for the resolved scale

\section{Greek symbols}

$\alpha \quad$ Thermal diffusivity, $\mathrm{m}^{2} \cdot \mathrm{s}^{-1}$

$\varepsilon \quad$ Turbulent eddy dissipation

$\varepsilon_{s g s} \quad$ sub-grid scale turbulent eddy dissipation

$\mu \quad$ Dynamic viscosity, $\mathrm{kg} \cdot \mathrm{m}^{-1} \cdot \mathrm{s}^{-1}$

$\mu_{t} \quad$ Subgrid-scale turbulent viscosity

$v \quad$ Kinematic viscosity, $\mathrm{m}^{2} . \mathrm{s}^{-1}$

$\rho \quad$ Density, $\mathrm{m}^{3} . \mathrm{Kg}^{-1}$

$\tau_{i j} \quad$ Subgrid-scale turbulent stresses, N. $\mathrm{m}^{-2}$

$\tau_{k k} \quad$ Isotropic part of subgrid-scale turbulent stresses, $\mathrm{N}$. $\mathrm{m}^{-2}$

$\delta_{i j} \quad$ Kronecker symbol

$\xi^{*} \quad$ Length fraction, $\mathrm{m}$

$\tau^{*} \quad$ Time scale, $\mathrm{s}$ 